\title{
Características citológicas de cistoadenocarcinoma papilar ovariano em um cão
}

\author{
Cytological Characteristics of Ovarian Papilary Cystadenocarcinoma in a Dog
}

\author{
Tamires Ramborger Antunes ${ }^{1 *}$, Renata Amarilha Valençoela Peixoto ${ }^{2}$, Raquel Mineko Matsuda ${ }^{2}$, \\ Gustavo Gomes de Oliveira', Alexandre Welzel da Silveira', Kelly Cristina da Silva Godoy', \\ Ariany Carvalho dos Santos ${ }^{3}$ \& Alda Izabel de Souza ${ }^{1}$
}

\begin{abstract}
Background: Ovarian papillary cystadenocarcinoma is a rare neoplasm associated with peritoneal implantation and malignant effusion. Most dogs are asymptomatic until the nodules become large and the abdominal volume is increased. From the clinical suspicion, the diagnosis can be obtained through imaging and histopathology, however, cytological analysis has become an alternative method for the early detection of this neoplasm. In order to demonstrate the importance of cytology in the diagnosis of ovarian neoplasms and its metastasis, it is reported a case of metastatic ovarian papillary cystadenocarcinoma in a dog.

Case: Female, intact, teckel, 5-year-old, with increased abdominal volume. Physical examination revealed ascites and intracavitary mass, abdominocentesis and fine needle puncture of the mass were performed for cytological evaluation. In the cavity fluid it was observed: dark red color, cloudy appearance, hematocrit of 35\%; (7.6 g / dL), pH (8.0), 22,000 nucleated cells $/ \mu \mathrm{L}$, marked cellularity of pleomorphic epithelial cells arranged in three-dimensional cohesive groups, sometimes in acinar or tubular pattern, nucleus with loose chromatin coarse, scarse to moderate cytoplasm, perinuclear halo, multiple and evident nucleoli compatible with carcinomatous neoplastic effusion. In the cytological evaluation of the tumor, epithelial cells were observed, with the same microscopic characteristics of the abdominal fluid. A laparotomy that did not show metastasis was performed, multiple nodes interspersed with cystic regions containing yellow-red fluid in the right ovary were visualized. Histopathology showed: neoplastic cells proliferation of ovarian glandular tissue, scarce cytoplasm, poorly delimited, nucleus ranging from oval to cylindrical with marked pleomorphism, evident nucleoli and loose chromatin, mitotic figures and papillary growth. Neoplastic cells forming irregular cavities with proteinaceous fluid, scarce connective tissue intermingling the cellular nest and areas of hemorrhage. Cytological and histopathological analyzes were compatible with ovarian papillary cystadenocarcinoma. After three months of excision, the dog returned with thoracic effusion that presented the same characteristics of the abdominal fluid, indicating metastasis.

Discussion: Metastasis and effusion were observed in $48 \%$ and $86 \%$ of dogs with this tumor, respectively. Cell exfoliation, release of fluid through the tumor capsule or rupture of cysts can result in transcelomic metastatic implants that exert pressure and obstruct peritoneal and diaphragmatic lymphatic vessels causing effusion. The macro and microscopic characteristics of the abdominal effusion reinforced the suspicion of neoplasia, and the cytomorphological evaluation of the tumor, which identified carcinomatous cells similar to that of the effusion, allowed the presumptive diagnosis of the neoplasia. The macroscopic presence of multiple nodes interspersed with cystic regions containing red fluid in the right ovary, identified after surgical excision, reinforced the cytologic diagnosis. Histopathological examination identified wellestablished microscopic features that allowed the definitive and confirmatory diagnosis of neoplasia. Radiological analysis of the chest was not enough to detect the metastasis diagnosed by effusion analysis, however, small nodules (less than 6 $\mathrm{mm}$ ) are difficult to identify by imaging. Thus, it is important to emphasize the importance of cytological evaluation of tumor and effusions for detection of neoplastic cells for the diagnosis of intracavitary neoplasia and metastasis.
\end{abstract}

Keywords: carcinoma, ovarian, cytology.

Descritores: carcinoma, ovário, citologia. 


\section{INTRODUÇÃO}

As neoplasias ovarianas de origem primária são incomuns em animais domésticos [5,6] e possuem diferentes tipos de classificação de acordo com suas características histogenéticas [9]. Tumores de origem epitelial representam $46 \%$ destas neoplasias, com maior frequência de tipos malignos [5,6,9].

O principal fator envolvido no desenvolvimento dessas massas ovarianas em cadelas consiste na administração de estrógenos por tempo prologando [6], no entanto, a causa exata ainda é desconhecida [1]. A maioria dos animais é assintomático, até o momento em que os nódulos adquirem grandes dimensões e aumento de volume abdominal é observado [5]. A partir da suspeita clínica, o diagnóstico pode ser obtido por meio de exames de imagem e histopatologia, contudo, a utilização da análise citológica tem se tornado um método alternativo para detecção precoce das neoplasias ovarianas $[2,4,5,8,9]$. O objetivo com este trabalho é apresentar um caso de cistoadenocarcinoma papilar ovariano metastático em cão diagnosticado por meio de análise citopatológica.

\section{CASO}

Um animal da espécie canina, fêmea não castrada, teckel, com 5 anos de idade, foi encaminhada para atendimento devido à presença de aumento de volume abdominal há aproximadamente 60 dias. Durante o exame físico, constatou-se presença de líquido abdominal e massa multilobulada intracavitária em região abdominal lateral direita. Para análise citológica, realizou-se abdominocentese com obtenção de amostra da efusão e punção aspirativa por agulha fina (PAAF) do tumor, via percutânea, não guiada. Amostra sanguínea para avaliação hematológica e mensuração de parâmetros bioquímicos (albumina, alanina aminotransferase, creatinina, fosfatase alcalina e ureia) também foi obtida.

$\mathrm{Na}$ análise do fluído observou-se coloração vermelho escuro e aspecto turvo, hematócrito de $35 \%$, elevada concentração de proteína $(7,6 \mathrm{~g} / \mathrm{dL}), \mathrm{pH}$ alcalino $(8,0)$ e aproximadamente 22.000 células nucleadas/ $\mu \mathrm{L}$. Na avaliação citomorfológica, foi notado marcada celularidade de células epiteliais pleomórficas arredondadas a poliédricas com um único núcleo apresentando cromatina frouxa à grosseira, citoplasma escasso a moderado e, ocasionalmente, com halo citoplasmático perinuclear (células em sinete) e nucléolos evidentes e múltiplos (Figura 1A). Essas células arranjavam-se formando grupos coesivos tridimensionais em padrão tubular ou acinar (Figura 1B). Tais achados foram compatíveis com efusão neoplásica do tipo carcinomatosa.

$\mathrm{Na}$ análise citológica do tumor, foram observadas células epiteliais com as mesmas características identificadas na análise do líquido abdominal. Além disso, material amorfo extracelular eosinofílico e macrófagos contendo grânulos de hemossiderina e cristais de hematoidina também foram visualizados (Figura 1C). Os achados citológicos em associação com as características macroscópicas foram compatíveis com os já registrados na literatura para cistoadenocarcinoma papilar ovariano [2,10].

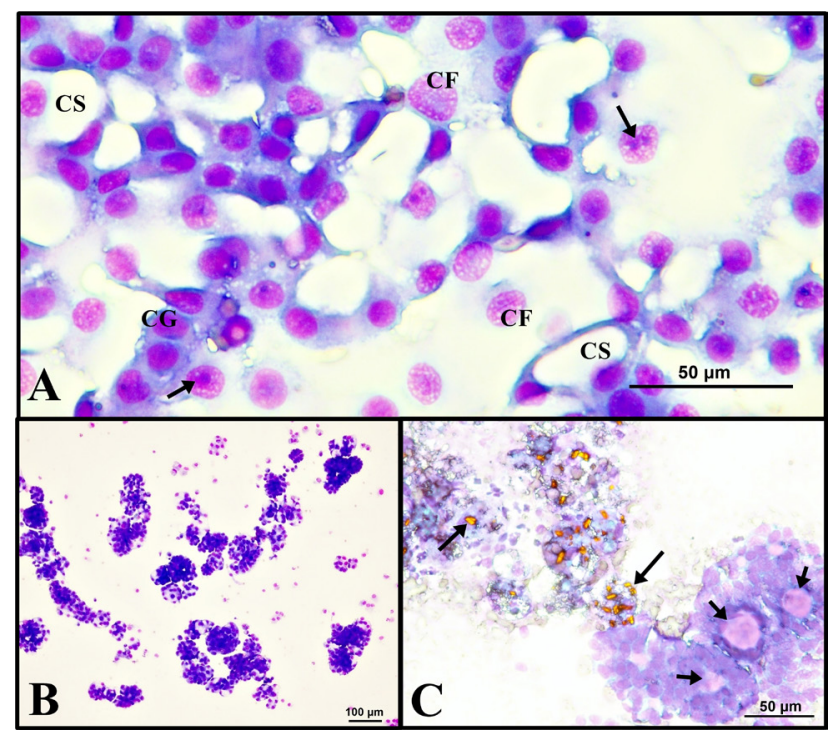

Figura 1. Cistoadenocarcinoma Papilar Ovariano, análise citológica. A- Presença de células epiteliais pleomórficas arredondadas a poliédricas com um único núcleo apresentando cromatina frouxa $(\mathrm{CF})$ à grosseira $(\mathrm{CG})$, citoplasma escasso a moderado com halo perinuclear - células em sinete (CS) - e nucléolos evidentes e múltiplos (setas) $[$ Obj. 40x ; Barra $=50$ $\mu \mathrm{m}]$. B- Marcada celularidade de células epiteliais pleomórficas arranjadas em grupos coesivos tridimensionais [Obj. 10x ; Barra $=100 \mu \mathrm{m}]$. C- Material extracelular eosinofílico (setas curtas) associado a células epiteliais em padrão acinar e macrófagos contendo grânulos de hemossiderina e cristais de hematoidina (setas longas). Coloração Panótico®. [Obj. 40x ; Barra = $50 \mu \mathrm{m}$ ].

Dados do hemograma e de todos os parâmetros bioquímicos séricos estavam dentro do intervalo de referência para a espécie. $\mathrm{O}$ animal foi encaminhado para excisão cirúrgica do tumor e laparotomia exploratória, identificando-se ausência de evidência de metástases na cavidade abdominal. Macroscopicamente observou-se acentuado aumento de volume em região de ovário direito (Figura 2A), que apresentava múltiplos nódu- 
los intercalados com regiões císticas contendo fluído vermelho-amarelado (Figura 2B). Para confirmação do diagnóstico inicial a peça tumoral foi encaminhada para análise histopatológica.

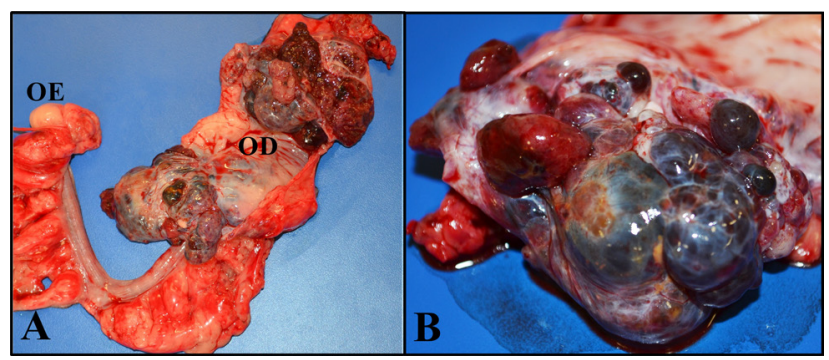

Figura 2. Cistoadenocarcinoma Papilar Ovariano, macroscopia. Observa-se acentuado aumento de volume em região de ovário direito (A) e presença de multinodulações (B) intercaladas com regiões císticas. Abreviações: OE: ovário esquerdo; OD: ovário direito.

No exame histopatológico constatou-se proliferação de células neoplásicas do tecido glandular ovariano. Essas células apresentavam citoplasma escasso e pouco delimitado, núcleo variando de oval a cilíndrico com acentuado pleomorfismo nuclear, 1-3 nucléolos evidentes e cromatina frouxa (Figura 3A). Em média, três figuras de mitose foram observadas em campo de 40x. O crescimento era predominantemente papilar (Figura 3B) e, por vezes, compacto. As células neoplásicas também se arranjavam formando cavidades irregulares contendo fluído proteináceo (Figura 3C). Escasso tecido conjuntivo entremeando o ninho celular e áreas de hemorragia também foram observadas. Esses achados foram compatíveis com cistoadenocarcinoma papilar ovariano, comprovando o diagnóstico citológico.

Aproximadamente três meses após a excisão cirúrgica o paciente retornou apresentando anorexia, dispneia e efusão torácica. Toracocentese e encaminhamento da amostra do fluído para análise laboratorial foram realizados. As mesmas características físicas, quantitativas, químicas e citológicas obtidas na avaliação do fluido peritoneal foram identificadas, indicando quadro de metástase a partir do cistoadenocarcinoma papilar ovariano. Ao exame radiológico, nenhuma lesão compatível com massa tumoral foi detectada.

Instituiu-se terapia conservadora, com realização de drenagens periódicas do líquido torácico, uma vez que o proprietário recusou a realização da quimioterapia indicada. A condição clínica do animal se deteriorou ao longo do tempo, até o momento que o mesmo veio a óbito em seu domicílio, impossibilitando a realização do exame postmortem.

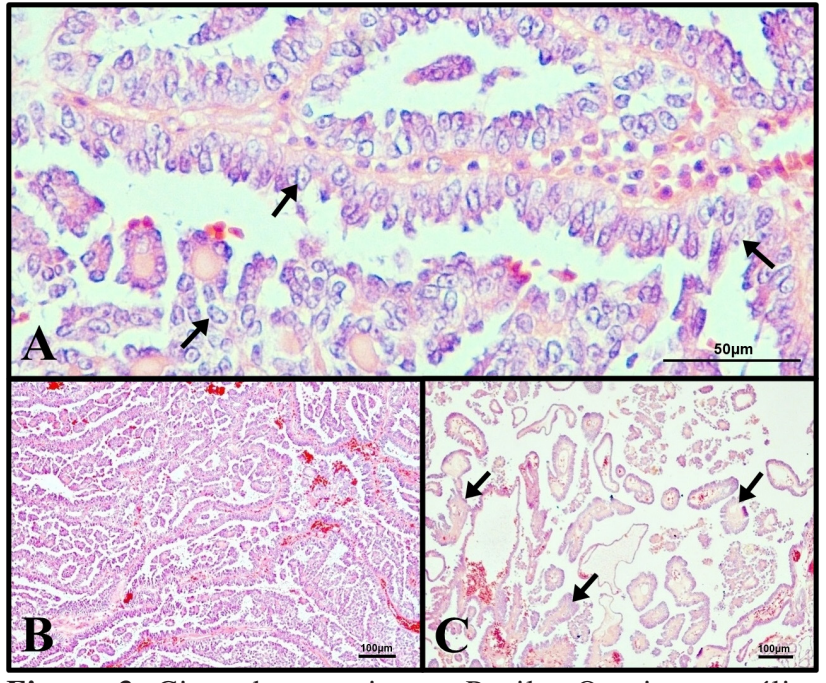

Figura 3. Cistoadenocarcinoma Papilar Ovariano, análise histopatológica. A- Observam-se células epiteliais pleomórficas apresentando cromatina nuclear frouxa e nucléolos evidentes [Obj. 40x ; Barra $=50 \mu \mathrm{m}]$. B- Células epiteliais neoplásicas em arranjo papilar e formando cordões. Focos hemorrágicos estão presentes [Obj. 10x ; Barra = $100 \mu \mathrm{m}$ ]. C- Notam-se áreas de cavidades irregulares contendo fluído proteináceo (setas). Coloração H\&E. [Obj. 10x ; Barra $=100 \mu \mathrm{m}$ ].

\section{DISCUSSÃO}

O cistoadenocarcinoma papilar ovariano é uma neoplasia maligna que frequentemente está associada com implante peritoneal e formação de derrame maligno [5]. Em um estudo realizado anteriormente constatou-se metástase em $48 \%$ (10/21) dos animais [7]. Também já foi identificada efusão em $86 \%$ (6/7) dos cães diagnosticados para esse tipo de tumor [2]. Esfoliação de células, liberação de fluído por meio da cápsula do tumor edemaciado ou ruptura de cistos podem resultar em implantes metastáticos transcelômicos que exercem pressão e obstruem vasos linfáticos peritoneais e diafragmáticos causando efusão [6], também identificada neste relato.

$\mathrm{Na}$ análise do fluído abdominal, a presença de coloração vermelho escuro, aspecto turvo, alta concentração proteica e celularidade, pH alcalino e hematócrito de $35 \%$ reforçaram a suspeita de neoplasia, uma vez que efusões neoplásicas frequentemente são exsudatos hemorrágicos, tendem a expressar reações mais alcalinas e alguns tipos de tumores sofrem esfoliação de células neoplásicas, tornando a efusão hipercelular [10]. Além disso, a avaliação citomorfológica do derrame cavitário e da PAAF do tumor, com identificação de células carcinomatosas apresentando características compatíveis com as descritas anteriormente [2], em 
associação com as informações clínico-laboratoriais permitiram o diagnóstico presuntivo da neoplasia.

Anemia normocítica normocrômica e leucocitose por linfocitose, leucograma de stress, diminuição das concentrações séricas de proteína total e globulinas e aumento de ureia, creatinina, eletrólitos (sódio, potássio e cloro), cálcio, creatina quinase e aspartatoaminotransferase já foram descritas, bem como eritrocitose, hiperproteinemia e hiperalbuminemia associadas à desidratação $[1,3,4,8,11]$, contudo, nenhuma alteração foi identificada no presente relato, sugerindo-se ausência de comprometimento sistêmico induzido pelo tumor.

A presença macroscópica de múltiplos nódulos intercalados com regiões císticas contendo fluído vermelho-amarelado no ovário direito, identificados pós excisão cirúrgica, reforçaram o diagnóstico citológico, já que esses achados macroscópicos foram observados por outros autores [3,4,8,11].

No exame histopatológico identificou-se células epiteliais pleomórficas em arranjo predominantemente papilar e por vezes formando cavidades irregulares contendo fluído proteináceo, que são características microscópicas bem estabelecidas que permitiram o diagnóstico confirmatório da neoplasia $[1,3,4,6]$.

A análise radiológica torácica não foi suficiente para detecção da metástase diagnosticada a partir da análise da efusão, contudo, nódulos pequenos (inferiores a $6 \mathrm{~mm}$ ) são de difícil identificação por meio do exame de imagem [12], enfatizando a importância da análise citológica de derrames cavitários como exame complementar.

A avaliação citológica das efusões e do material aspirado do tumor foi de fundamental importância para a detecção das células neoplásicas e confirmação de metástase, permitindo a determinação da etiologia de maneira precoce, ainda que a histopatologia seja fundamental para a confirmação do diagnóstico.

Acknowledgements. The authors would like thank the FUNDECT for scholarships granted.

\section{REFERENCES}

1 Ajadi A.T., Antia E.R. \& Akang E.E. 2011. Cystadenocarcinoma arising from ovary in a three-year-old doberman bitch. International Journal of Morphology. 29(3): 988-991.

2 Bertazollo W., Dell'Orco M., Bonfanti U., Delorenzi D., Masserdotti C., De Marcos D., Caniatti M. \& Roccabianca P. 2004. Cytological features of canine ovarian tumours: a retrospective study of 19 cases. Journal of Small Animal Practice. 45: 539-545.

3 Goodwin J.K., Hager D., Phillips L. \& Lyman R. 1990. Bilateral ovarian adenocarcinoma in a dog: ultrasonographicaided diagnosis. Veterinary Radiology. 31(5): 265-267.

4 Hori Y., Uechi M., Kanakubo K. \& Oyamada T. 2006. Canine ovarian serous papillary adenocarcinoma with neoplastic hypercalcemia. Journal of Veterinary Medical Science. 68(9): 979-982.

5 Klein M.K. 2007. Tumors of the female reproductive system. In: Withrow S.J. \& Vail D.M. (Eds). Withrow and MacEwen's, Small Animal Clinical Oncology. 4th edn. Philadelphia: Saunders Company, pp.610-618.

6 MacLachlan N.J. 1987. Ovarian disorders in domestic animals. Environmental Health Perspective. 27(73): 27-33.

7 Patnaik A.K. \& Greenlee P.G. 1987. Canine ovarian neoplasms: a clinicopathologic study of 71 cases, including histology of 12 granulosa cell tumors. Veterinary Pathology. 24(6): 509-514.

8 Petterino C., Modesto P. \& Ratto A.A. 2010. Bilateral ovarian psammomatous papillary cystic adenocarcinoma in a german shepherd bitch. Comparative Clinical Pathology. 19(4): 389-395.

9 Sforna M., Brachelente C., Lepri E. \& Mechelli L. 2003. Canine ovarian tumours: a retrospective study of 49 cases. Veterinary Research Communications. 27(Suppl.1): 359-361.

10 Solano-Gallego L. 2011. Sistema reprodutivo. In: Raskin R.E. \& Meyer D.J. (Eds). Citologia clínica de cães e gatos, atlas colorido e guia de interpretação. 2.ed. Rio de Janeiro: Elsevier, pp.274-308.

11 Simon S.M. \& Kumar R.S. 2012. Surgical management of ovarian papillary adenoma in a bitch. Tamilnadu Journal. Veterinary \& Animal Sciences. 8(6): 329-331.

12 Thrall D.E. 2012. Textbook of veterinary diagnostic radiology. 6th edn. Saint Louis: Elsevier, 850p. 